\title{
Catalysis, Kinetic and Mechanistical Studies for the Transformation of Ethylene Glycol by Alumina and Silica Gel under Autogenous Pressure and Solvent-free Conditions
}

\author{
Taoufik Rohand ${ }^{1, \star}$ and Kiyoshi Tanemura ${ }^{2}$ \\ ${ }^{1}$ Laboratory of Analytical and Molecular Chemistry, Faculty Polydisciplinaire of Safi, Route Sidi Bouzid BP 4162, \\ 46000 Safi, University Cadi Ayyad Marrakech, Morocco \\ ${ }^{2}$ Chemical Laboratory, School of Life Dentistry at Niigata, Nippon Dental University, Hamaura-cho, \\ Niigata 951-8580, Japan \\ ${ }^{*}$ Corresponding author: E-mail: Taoufik.Rohand@uca.ac.ma
}

Received: 09-26-2020

\begin{abstract}
A kinetic and mechanistical studies of the new pathway for competitive transformation of ethylene glycol by alumina and silica gel have been described. Commercial alumina (Al com), synthetic alumina ( $\mathrm{Al} \mathrm{syn),} \mathrm{commercial} \mathrm{silica} \mathrm{gel} \mathrm{(Si} \mathrm{com)}$ and synthetic silica gel (Si syn) were used for the transformation of ethylene glycol to a mixture of diethylene glycol, 1,4-dioxane and 2-methyl-1,3-dioxolane via acetaldehyde by heating at $150{ }^{\circ} \mathrm{C}$ under autogenous pressure without solvent. The results show that the yield of these three products strongly depends on the nature of the used catalyst and the reaction time.
\end{abstract}

Keywords: Dioxolanes; ethylene glycol; dimerization; acetalization; environmental effects; kinetic studies

\section{Introduction}

In recent years, the use of silica gel as a catalyst in environmentally friendly conditions became an interesting topic for investigations in organic chemistry reactions. In the same way, the use of pollutant and harmful organic solvents has been replaced by solvent-free reactions which became very advantageous alternatives. ${ }^{1-3}$ However, protic acids are well-known to suffer from a number of shortcomings, including their corrosive and noxious nature. ${ }^{4,5}$ The recent move towards green chemistry has seen silica gel and alumina gradually replacing mineral acids in the synthesis of organic compounds. Indeed, these non-polluting heterogeneous catalysts possess numerous advantages such as ready availability, efficient recycling, low cost and ease of separation from crude reaction mixtures by simple filtration. ${ }^{6-8}$ For example, the condensation of epoxystyrene with benzylmethylamine, the cyclization of enones, the vinylogous Michael double additions, the transformation of 1-amino-2-ketoesters and of 4-amino-3,4-dihydro-2H-1,4-thiazines have all been carried out in the presence of silica gel. ${ }^{9-11}$ Alumina also catalyses the oxidation of alcohols to ketones by trichlo- roacetic acid, the dehydration of alcohols to alkenes, the synthesis of isoxazolines and of 1,2-aminoalcohols. ${ }^{12-17}$ Ethylene glycol is frequently used in organic synthesis to protect aldehydes and ketones, enabling other functional groups in the molecule to undergo chemoselective transformations. These acetalization and ketalization reactions are typically carried out in ecologically harmful organic solvent, in the presence of noxious protic acids at various temperatures, and typically, at atmospheric pressure. ${ }^{18-20}$

In this work, we have continued our investigation on the use of silica gel in chemical reactions, ${ }^{12-14}$ so we have been led to advance a new method of the synthesis of 2-methyl-1,3-dioxolane (5) by the conversion of ethylene glycol on solid catalysts such as silica gel and alumina while meeting the requirements of green chemistry.

\section{Experimental}

\section{1. General}

NMR spectra were recorded on a Bruker AC spectrometer $\left({ }^{1} \mathrm{H}\right.$ at $300 \mathrm{MHz}$ and ${ }^{13} \mathrm{C}$ at $\left.75 \mathrm{MHz}\right)$ in $\mathrm{CDCl}_{3}$ 
solution. The chemical shift $(\delta)$ of the signals described is expressed in ppm relative to TMS taken as the internal reference. The following abbreviations are used: s: singlet, $\mathrm{d}$ : doublet, t: triplet, m: multiplet, l: large. The coupling constants $(J)$ are expressed in $\mathrm{Hz}$. The reagents were from $\mathrm{Al}-$ drich. The silica gel was commercial type Merck 60 (70-230 mesh) and alumina was an Aldrich commercial product. In all experiments, ethylene glycol (1) present in the crude reaction product was removed by adding water to the crude reaction mixture. After the treatment, the mixture of carbonyl compounds 4 and 2-methyl-1,3-dioxolane (5) was recovered. The yields of products $\mathbf{5}$ were estimated from the ${ }^{1} \mathrm{H}$ and ${ }^{13} \mathrm{C}$ NMR spectra of the crude reaction mixtures using an internal reference in order to avoid their decomposition during chromatographic purification, as reported in the other work. ${ }^{21}$ Compounds $\mathbf{2}, \mathbf{3}$ and $\mathbf{5}$ were identified by comparing their ${ }^{1} \mathrm{H}$ and ${ }^{13} \mathrm{C}$ NMR spectra with authentic samples marketed by Aldrich. We used the following abbreviations in the text: Si syn: synthetic silica gel, Si com: commercially available silica gel, $\mathrm{Al}$ syn: synthetic alumina, Al com: commercially available alumina.

\section{2. Synthesis of 2-Methyl-1,3-dioxolane (5) Using Sulfuric Acid}

Procedure at atmospheric pressure. Ethylene glycol (1) $(7.67 \mathrm{~g}, 124 \mathrm{mmol})$ and $\mathrm{H}_{2} \mathrm{SO}_{4}$ (4\% by mass) were placed in a flask $(50 \mathrm{~mL})$ equipped with a reflux condenser and then heated at $196^{\circ} \mathrm{C}$ for $3 \mathrm{~h}$. After cooling, $20 \mathrm{~mL}$ of water was added to the crude mixture to remove residual ethylene glycol. The aqueous solution was extracted with diethyl ether $(3 \times 50 \mathrm{~mL})$. The organic phases were combined and then dried over $\mathrm{MgSO}_{4}$. After filtration and evaporation of the ether in vacuo, the mixture of $\mathbf{2}$ and $\mathbf{3}$ was recovered. The yields of products $\mathbf{2}$ and $\mathbf{3}$ are displayed in Table 1.

Procedure under pressure. Ethylene glycol (1) (7.67 g, $124 \mathrm{mmol}$ ) and $\mathrm{H}_{2} \mathrm{SO}_{4}$ (4\% by mass) were placed in an autoclave $(100 \mathrm{~mL})$. The sealed reactor was heated at 150 ${ }^{\circ} \mathrm{C}$ for $3 \mathrm{~h}$ or for $24 \mathrm{~h}$. After cooling, the residue was treated in the same manner as described above. The yields of products $\mathbf{2}$ and $\mathbf{3}$ are listed in Table 1 .

\section{3. Synthesis of 1,3-Dioxolanes by Silica Gel}

Procedure at atmospheric pressure. Ethylene glycol (1) $(7.67 \mathrm{~g}, 124 \mathrm{mmol})$ and $0.1 \mathrm{~g}$ of silica gel were placed in a flask $(50 \mathrm{~mL})$ equipped with a reflux condenser and the whole was heated at $196{ }^{\circ} \mathrm{C}$ for $120 \mathrm{~h}$. After cooling and separating the silica gel by filtration, the residue was treated in the same manner as described above. Diethylene glycol (2) was obtained in a yield of $1 \%$ (Table 1 ).

Procedure under pressure. Ethylene glycol (1) (7.67 $\mathrm{g}, 124 \mathrm{mmol})$ and $0.1 \mathrm{~g}$ of silica gel were placed in an autoclave $(100 \mathrm{~mL})$. The sealed reactor was heated to $150^{\circ} \mathrm{C}$ for various amounts of time. After cooling and separating the silica gel by filtration, the residue was treated in the same manner as described above. The yields of products $\mathbf{2}$ and $\mathbf{5}$ are listed in Table 1.

\section{4. Reaction Under Atmospheric Pressure}

In a ground-glass flask equipped with a refrigerant and a magnetic stirrer, ethylene glycol (1) $(6.9 \mathrm{~mL}, 7.68 \mathrm{~g}$, $0.124 \mathrm{mmol})$ was introduced to which $0.307 \mathrm{~g}(1.3 \%$ by mass) of concentrated sulfuric acid was added. The mixture was heated under reflux for $1 \mathrm{~h}$ and $3 \mathrm{~h}$ and under atmospheric pressure. After cooling to room temperature, $20 \mathrm{~mL}$ of water was added to the reaction crude to remove ethylene glycol (1). The aqueous phase was extracted by diethyl ether $(3 \times 20 \mathrm{~mL})$ and then the organic phase was dried over $\mathrm{MgSO}_{4}$. After filtration and evaporation of the solvent under vacuum, the mixture of diethylene glycol (2) and 1,4-dioxane (3) was recovered.

\section{5. Autogenous Pressure Reaction}

Ethylene glycol (1) $(6.9 \mathrm{~mL}, 7.68 \mathrm{~g}, 0.124 \mathrm{mmol})$ and concentrated sulfuric acid $(0.307 \mathrm{~g}, 1.3 \%$ by weight) were placed in a sealed autoclave and the mixture was heated to $150{ }^{\circ} \mathrm{C}$ (oil bath temperature) under autogenous pressure for varying times. After cooling the reactor to room temperature, $20 \mathrm{~mL}$ of water was added to the filtrate to remove the remaining ethylene glycol (1) in the reaction mixture. The aqueous phase was extracted by diethyl ether $(3 \times 20 \mathrm{~mL})$ and then the organic phase was dried over $\mathrm{MgSO}_{4}$. After filtration and evaporation of the solvent under vacuum, the mixture of diethylene glycol (2) and 1,4-dioxane (3) was recovered.

\section{6. Preparation of Synthetic Silica}

Synthetic silica (Si syn) was obtained by precipitating the silica from a sodium silicate solution of concentration [Si] $=1.667 \mathrm{~mol} \cdot \mathrm{L}^{-1}$ by adding, drop by drop and with agitation, $2 \mathrm{M} \mathrm{HCl}$ until a pH of 4 was reached. Si syn silica was recovered after successive washing to remove sodium chloride and drying at a temperature of $100{ }^{\circ} \mathrm{C}$ for a few hours. Sodium silicate was obtained by alkaline fusion of extra-silica sand, originating from the Safi region in Morocco, with sodium carbonate with a $\mathrm{SiO}_{2} / \mathrm{Na}_{2} \mathrm{O}$ ratio of 1 .

\section{7. Preparation of Synthetic Silica}

The procedure followed is similar to the method described by Noor Abdulateef Ghulam. ${ }^{22}$

\section{8. Reaction of Catalysts on Ethylene Glycol}

(1)

Ethylene glycol (1) $(7.68 \mathrm{~g}, 124 \mathrm{mmol})$ and the catalyst $(0.1 \mathrm{~g}, 1.3 \%$ by weight $)$ were placed in a sealed auto- 
clave and heated to $150{ }^{\circ} \mathrm{C}$ (oil bath temperature) under autogenous pressure for varying times. After cooling the reactor to room temperature, the catalyst was separated by filtration. $20 \mathrm{~mL}$ of water was added to the filtrate to remove the remaining ethylene glycol (1) in the reaction mixture. The aqueous phase was extracted by diethyl ether $(3 \times 20 \mathrm{~mL})$ and then the organic phase was dried over $\mathrm{MgSO}_{4}$. After filtration and evaporation of the solvent under vacuum, a mixture of diethylene glycol (2), 1,4-dioxane (3) and 2-methyl-1,3-dioxolane (5) was recovered.

\section{Results and Discussion}

It is known that distillation of ethylene glycol (1) in the presence of sulfuric acid in small proportions ( $4 \%$ by mass) leads to three products. ${ }^{23-25} 1,4$-Dioxane (3) is the majority product of this reaction while diethylene glycol (2), acetaldehyde (4) and 2-methyl-1,3-dioxolane (5) are obtained in low yields (Scheme 1).

From our part, we have shown in this work that the heating of this same mixture at high temperatures for $2 \mathrm{~h}$ and under different pressures and with three different acids, i.e. formic acid, acetic acid and sulfuric acid, allows the formation of diethylene glycol (2) as the majority product (Table 1, entries 1, 3 and 5). It is noted that the prolonga- tion of the duration of the heating of this reaction mixture from $2 \mathrm{~h}$ to 2 days considerably increased the yield of dimer 2 while keeping 1,4-dioxane (3) as a minor product of this reaction, whereas acetaldehyde (4) and 2-methyl-1,3-dioxolane (5) were not obtained (Table 1, entries 2 , 4 and 6). However, the best results were obtained using sulfuric acid as the catalyst.

These unexpected results then motivated us to generalize this type of conversion by using imported and commercial solid catalysts, such as commercial silica gel ( $\mathrm{Si}$ com) (Aldrich) and a local catalyst such as inexpensive synthetic Moroccan silica (Si syn) and easy to prepare from sand originating from the sea side of Safi in Morocco, ${ }^{4}$ while the alumina is commercial ( $\mathrm{Al} \mathrm{com}$ ) (Aldrich) (Table 2), also alumina ( $\mathrm{Al}$ syn) was synthesised following the standard procedure published by Ghulam. ${ }^{22}$ It is interesting to note that these three heterogeneous solid catalysts exhibit Brønsted and Lewis acidic sites at their active surfaces.

The cation exchange capacities (CEC) then make it possible to classify in decreasing order of reactivity with respect to ethylene glycol (1): $\mathrm{Si}$ syn $>\mathrm{Si} \mathrm{com}>\mathrm{Al} \mathrm{com}>$ Al syn (Si syn: synthetic silica gel, $\mathrm{Si}$ com: commercially available silica gel, Al syn: synthetic alumina, Al com: commercially available alumina).

Thus, heating the ethylene glycol (1) in an autoclave at a constant temperature of $150{ }^{\circ} \mathrm{C}$ (oil bath temperature)<smiles>OCCO</smiles>

1

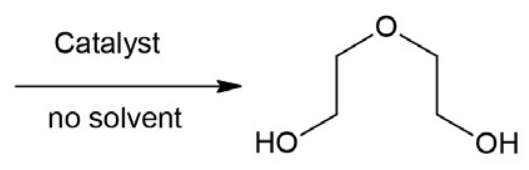

2<smiles>C1COCCO1</smiles>

3

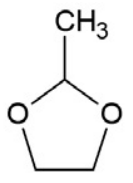

5

Scheme 1.

Table 1. Conversion of ethylene glycol (1) in homogenous acid medium.

\begin{tabular}{cccccccc}
\hline Entry & Catalyst & $\boldsymbol{T}\left({ }^{\circ} \mathbf{C}\right)$ & Time (h) & $\mathbf{1 ~ ( \% )}$ & $\mathbf{2 ( \% )}$ & $\mathbf{3}(\mathbf{\%})$ & $\mathbf{4}(\mathbf{\%})$ \\
\hline 1 & $\mathrm{H}_{2} \mathrm{SO}_{4}(4 \% w t)$. & $196^{\mathrm{a}}$ & 3 & 95 & 4 & 1 & - \\
2 & $\mathrm{H}_{2} \mathrm{SO}_{4}(4 \% \mathrm{wt})$. & $150^{\mathrm{b}}$ & 3 & 75 & 16 & 9 & - \\
3 & $\mathrm{H}_{2} \mathrm{SO}_{4}(4 \%$ wt.) & $150^{\mathrm{b}}$ & 24 & 26 & 65 & 9 & - \\
4 & Silica gel & 196 & 120 & 99 & 1 & - & - \\
5 & Silica gel & 150 & 3 & 100 & - & - & - \\
6 & Silica gel & 150 & 7 & 81 & - & - & 19 \\
\hline
\end{tabular}

a $\mathrm{P}$ atm: atmospheric pressure $(110 \mathrm{kPa})$. Reactor: $50 \mathrm{~mL}$ flask.

${ }^{b} \mathrm{P}$ auto: autogenic pressure $\left(\mathrm{P}\right.$ at $\left.150^{\circ} \mathrm{C}=153 \mathrm{kPa}\right)$.

\begin{tabular}{cccccc}
\hline Entry & Pressure & $\boldsymbol{T}\left({ }^{\circ} \mathbf{C}\right)$ & Catalyst & Time & Global Yield $\mathbf{~}^{\text {\%) }}$ \\
\hline 1 & P atm & 150 & $\mathrm{HCOOH}$ & $2 \mathrm{~h}$ & 5 \\
2 & $\mathrm{P}$ atg & 150 & $\mathrm{HCOOH}$ & 2 days & 12 \\
3 & $\mathrm{P}$ atm & 150 & $\mathrm{CH}_{3} \mathrm{COOH}$ & $5 \mathrm{~h}$ & 9 \\
4 & $\mathrm{P}$ atg & 150 & $\mathrm{CH}_{3} \mathrm{COOH}$ & 2 days & 28 \\
5 & $\mathrm{P}$ atm & 150 & $\mathrm{H}_{2} \mathrm{SO}_{4}$ & $5 \mathrm{~h}$ & 41 \\
6 & $\mathrm{P}$ atg & 150 & $\mathrm{H}_{2} \mathrm{SO}_{4}$ & $24 \mathrm{~h}$ & 93 \\
\hline
\end{tabular}

${ }^{a}$ The conversion of the ethylene glycol (1) using each catalyst separately. 
for $24 \mathrm{~h}$ under autogenous pressure and in the presence of these solid catalysts promotes the formation of the three products; 2-methyl-1,3-dioxolane (5) is the major product of this reaction while diethylene glycol (2) and 1,4-dioxane (3) are obtained in low yields (Table 2). The difference in the results reported in Tables 1 and 2 shows that the conversion of ethylene glycol (1) proceeds in a different way from the homogeneous to the heterogeneous medium. It is interesting to note that sulfuric acid ( $4 \% \mathrm{wt}$.) promotes the selective formation of dimer 2 while silica and alumina catalysts $(1.3 \% \mathrm{wt}$.) selectively transform ethylene glycol (1) into 2-methyl-1,3-dioxolane (5) (Fig. 1).

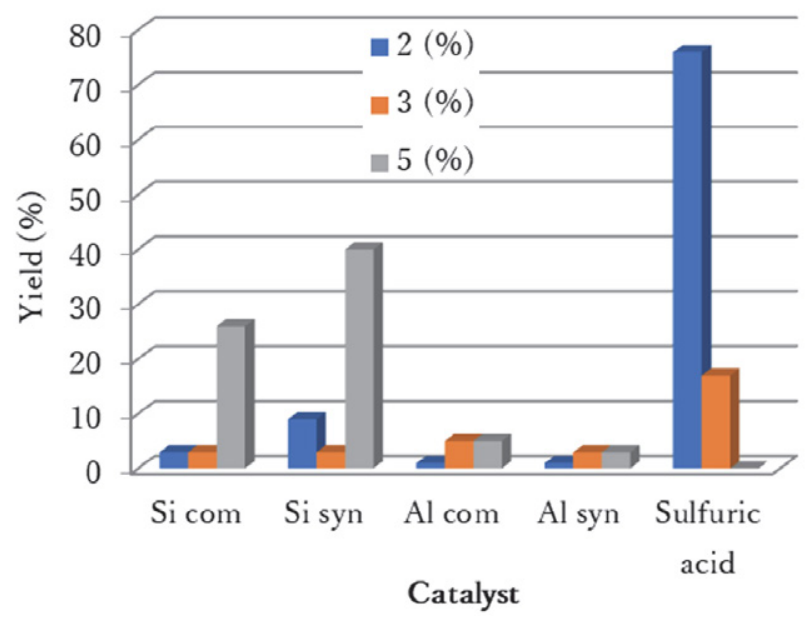

Figure 1. Evaluation of the yield of products $\mathbf{2}, \mathbf{3}$ and $\mathbf{5}$ in the presence of $\mathrm{H}_{2} \mathrm{SO}_{4}$ (4\% wt.) and of catalysts based on silica gel and alumina ( $1.3 \%$ wt.).

We can then conclude that the homogeneous medium accelerates the dimerization of ethylene glycol (1) to diol 2, which cyclising to 1,4-dioxane (3) while the heterogeneous medium promotes the dehydration of diol 1 to acetaldehyde (4), which in turn will be trapped by a second molecule of ethylene glycol (1) in excess to lead to 2-methyl-1,3-dioxolane (5) (Scheme 2).

From the results recorded above, we have found that commercial catalysts such as $\mathrm{Si}$ com silica gel and $\mathrm{Al}$ com alumina are not very active against ethylene glycol (1) (Table 2, entries 1 and 3), while synthetic Si syn silica being the catalyst promotes the formation of 2-methyl-1,3-dioxolane (5) in $40 \%$ yield (Table 2, entry 2 ). In addition, Si syn synthetic silica proved to be the best catalyst in this series with an overall reaction efficiency of $51 \%$ (Fig. 2).

\section{1. Kinetic Study}

In order to better understand the transformation of ethylene glycol (1) in a heterogeneous environment, we conducted a kinetic study by means of catalysts $\mathrm{Al}$ com, $\mathrm{Si}$ com and Si syn, except $\mathrm{Al}$ syn due to the low efficiency at $150{ }^{\circ} \mathrm{C}$ under autogenous pressure and for variable times. Analysis of the appearance of the curves shown in Figures

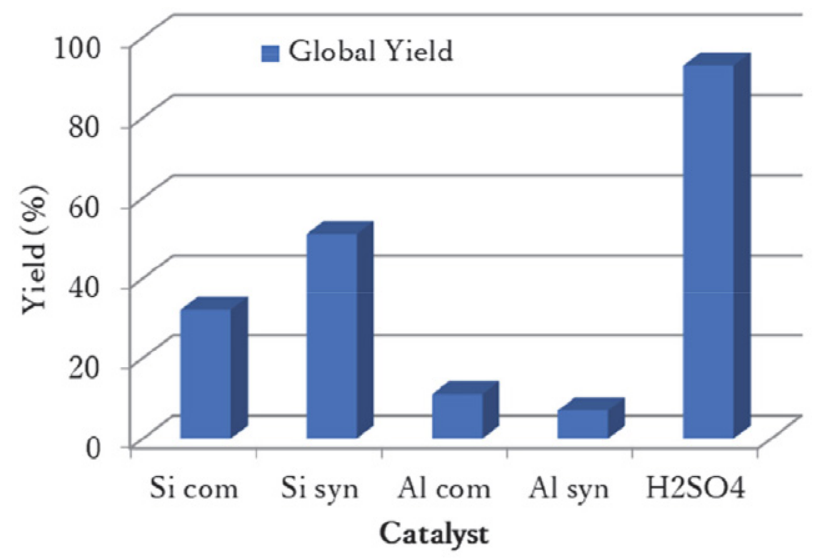

Figure 2. Evaluation of the overall yield in the presence of $\mathrm{H}_{2} \mathrm{SO}_{4}$ ( $4 \% \mathrm{wt}$.) and catalysts based on silica gel and alumina ( $1.3 \% \mathrm{wt}$.

Table 2. Transformation of ethylene glycol (1) by silica gel and alumina catalysts ${ }^{\mathrm{a}}$

\begin{tabular}{ccccccc}
\hline Entry & Catalyst & CEC $^{\mathbf{b}}$ & Global Yield $^{\mathbf{c}}(\mathbf{\%})$ & $\mathbf{2}(\mathbf{\%})$ & $\mathbf{3}(\mathbf{\%})$ & $\mathbf{4}(\mathbf{\%})$ \\
\hline 1 & Si com & 16 & 32 & 3 & 3 & 26 \\
2 & Si syn & 25 & 51 & 9 & 3 & 40 \\
3 & Al com & 10 & 11 & 1 & 5 & 5 \\
4 & Al syn & 21 & 7 & 1 & 3 & 3 \\
\hline
\end{tabular}

${ }^{\text {a }}$ Reaction conditions: temperature $150{ }^{\circ} \mathrm{C}$, time $24 \mathrm{~h}{ }^{\mathrm{b}}$ Cationic exchange capacity (meq/100 g).

${ }^{\mathrm{c}}$ The conversion of the ethylene glycol (1) using each catalyst separately.<smiles>CCCCCCC</smiles>

5

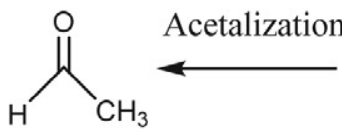

4<smiles>OCCO</smiles>

1

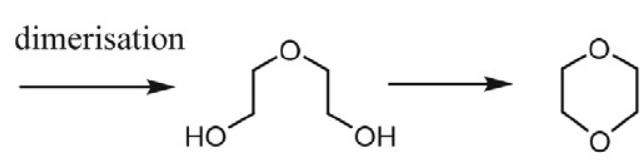

2

Scheme 2. 


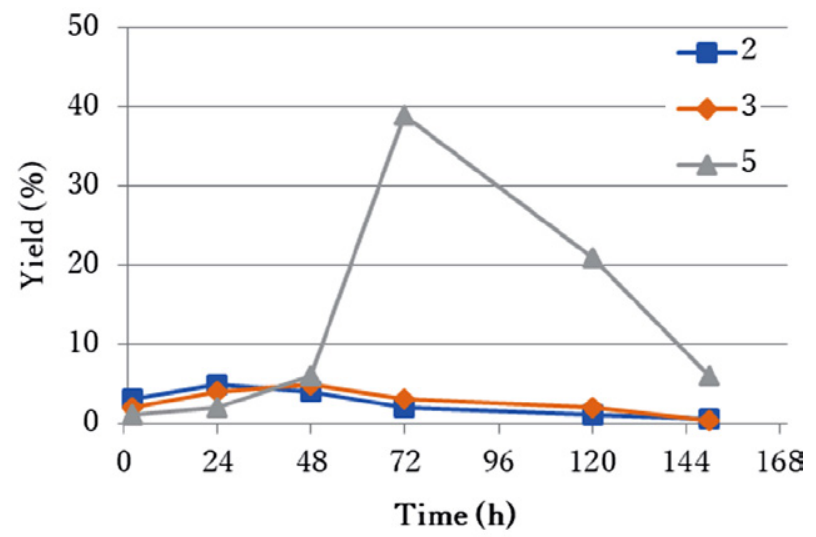

Figure 3. Evaluation of products $\mathbf{2 ,} \mathbf{3}$ and $\mathbf{5}$ formed in the presence of commercial alumina $\mathrm{Al}$ com.

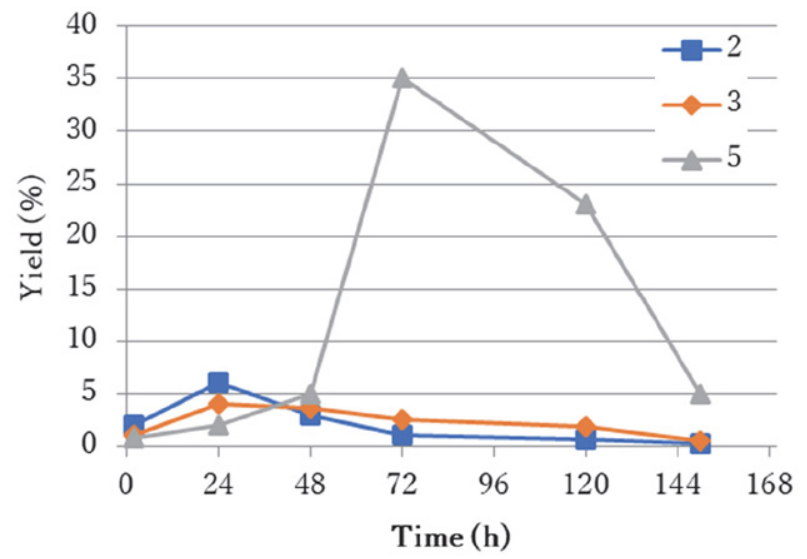

Figure 4. Evaluation of products $\mathbf{2}, \mathbf{3}$ and $\mathbf{5}$ formed in the presence of synthetic alumina Al syn.

3-6 indicates that the conversion of ethylene glycol (1) to diethylene glycol (2), 1,4-dioxane (3) and 2-methyl-1,3-dioxolane (5) depends closely on the nature of the used catalyst and the duration of the reaction. The formation of secondary products by the action of these three catalysts is a perceptible result.

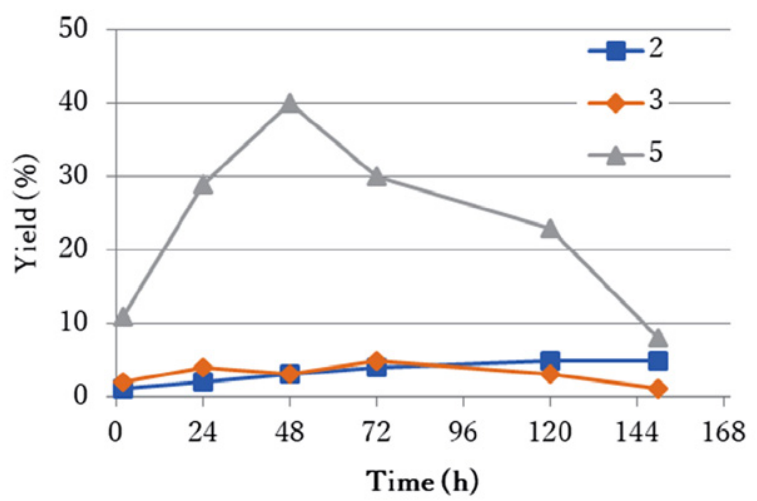

Figure 5. Evaluation of products $\mathbf{2 ,} \mathbf{3}$ and $\mathbf{5}$ formed in the presence of commercial silica Si com.

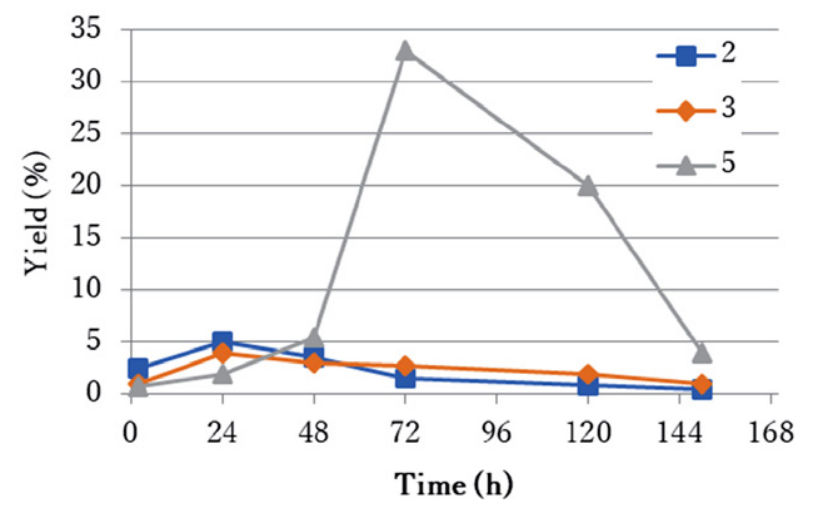

Figure 6. Evaluation of products $\mathbf{2 ,} \mathbf{3}$ and $\mathbf{5}$ formed in the presence of synthetic silica Si syn.

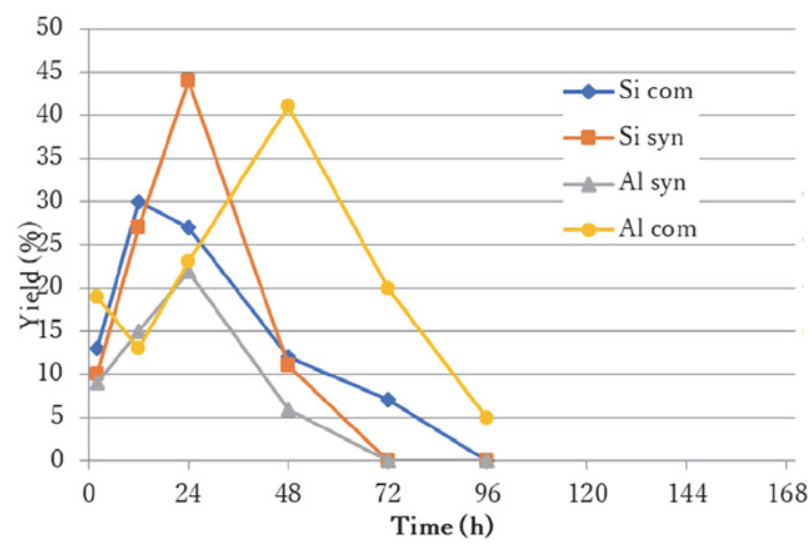

Figure 7. Evaluation of 2-methyl-1,3-dioxolane (5) according to the nature of the catalyst and the reaction time.

Indeed, we have noticed that dimerization products 2 and 3 are obtained in low yields not exceeding 7\% regardless of the nature of the used catalyst and the reaction time.

We have also noticed that compound $\mathbf{5}$ is the main product of these reactions; it is obtained with a yield of $38 \%$ in the presence of alumina $\mathrm{Al}$ com after $48 \mathrm{~h}$ of the reaction, $29 \%$ in the presence of silica gel Si com after $24 \mathrm{~h}$ of the reaction and $40 \%$ when using synthetic silica $S i$ syn after $48 \mathrm{~h}$ of the reaction (Fig. 7). The decrease in the yields of 5 is due to a decomposition.

We also found that the overall efficiency of the transformation of ethylene glycol (1) into products 2, 3 and 5 reached a maximum of $34 \%$ in the presence of alumina $\mathrm{Al}$ com after $72 \mathrm{~h}$ of the reaction, $22 \%$ in the presence of silica gel Si com after $24 \mathrm{~h}$ of the reaction and $44 \%$ in the presence of synthetic silica Si syn after $48 \mathrm{~h}$ of the reaction (Fig. 8).

It is interesting to note that the speed of the dimerization reaction is less important than that of the acetalization reaction (Figs. 3-6). Synthetic Moroccan silica Si syn therefore represents the promising catalyst because it promotes the yield of dimerization (11\%) and acetalization (40\%) products after $48 \mathrm{~h}$ of reaction (Fig. 6). We can thus conclude that Moroccan synthetic silica Si syn represents 


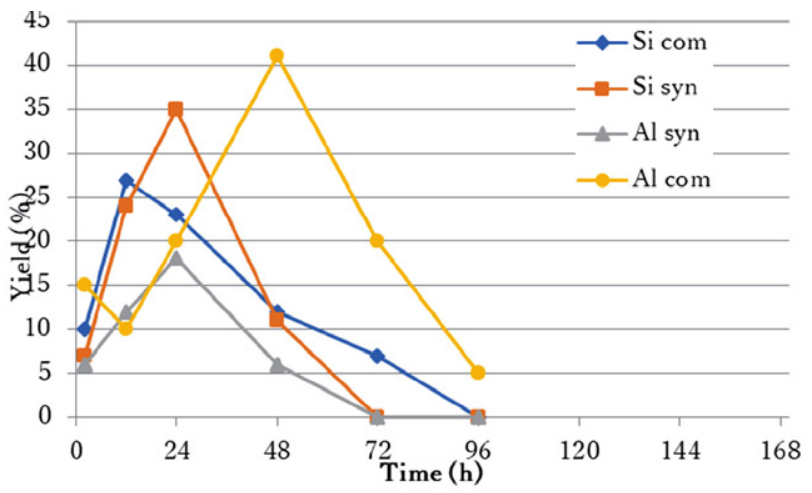

Figure 8. Evaluation of the overall efficiency according to the nature of the catalyst used.

the promising catalyst because it favours the highest yield for a relatively long reaction time.

\section{2. Spectroscopic Study}

Indeed, we noted that in the case of ethylene glycol (1) and 1,4-dioxane (3), the $\mathrm{C} 1$ and $\mathrm{C} 2$ carbon atoms have the same atomic charges and the same for the oxygen atoms $\mathrm{O} 1$ and $\mathrm{O} 2$ (Table 3).

In the cases of diethylene glycol (2), acetaldehyde (4) and 2-methyl-1,3-dioxolane (5) carbon atoms, C1, C2 and C3 do not have the same atomic charge values, identical for oxygen atoms $\mathrm{O} 1$ and $\mathrm{O} 2$ (Table 3). In addition, the lengths of the $\mathrm{C}-\mathrm{C}, \mathrm{C}-\mathrm{O}$ and $\mathrm{C}-\mathrm{H}$ bonds are closely related to the structure of the molecule under study (Table 3).

Finally, the nature of the atoms and the structure of the molecules have a significant effect on the dihedral angles of compounds 1-5 (Table 3 ).

Similarly, during the heating of ethylene glycol (1), two major intermediates were formed in situ, 1,4-oxirane (3) and acetaldehyde (4), which evolved differently to lead to products 2-5. The theoretical calculation of the NBO loads of these intermediates shows that the reaction evolves in the directions of formation of 2-methyl-1,3-dioxolane (5) from acetaldehyde (4), since the atomic carbon load of the $\mathrm{C}=\mathrm{O}$ group of acetaldehyde (4) (0.452) is higher than that of the carbons $(-0.080)$ of oxirane.

The addition of ethylene glycol (1) introduced in excess is then more favoured on the most electrophilic carbon of acetaldehyde (4) despite two oxirane carbons (Scheme 3).

On the other hand, the comparative spectroscopic study of ${ }^{1} \mathrm{H}$ NMR (Table 3 ) and ${ }^{13} \mathrm{C}$ NMR reveals that the differences in the chemical shifts of ${ }^{1} \mathrm{H}$ and ${ }^{13} \mathrm{C}$ NMR spectra of compounds 1-5 are closely dependent on their electronic effects.

Table 3. Some physical characteristics of ethylene glycol (1) and its derivatives 2-5

\begin{tabular}{|c|c|c|c|c|}
\hline Products & Atomic charge & Dihedral angle & Bond length & ${ }^{1} \mathbf{H}$ NMR \\
\hline \multirow{5}{*}{1} & $\mathrm{C} 1=0.025$ & \multirow[t]{5}{*}{$\mathrm{O} 1 \mathrm{C} 1 \mathrm{C} 2 \mathrm{O} 2=179.86$} & $\mathrm{C} 1-\mathrm{O} 1=1.462$ & $\mathrm{CH}_{2} \mathrm{OH}$ \\
\hline & $\mathrm{C} 2=0.025$ & & $\mathrm{C} 2-\mathrm{O} 2=1.462$ & $3.06 \mathrm{ppm}$ \\
\hline & $\mathrm{O} 1=0.416$ & & $\mathrm{C} 1-\mathrm{C} 2=1.512$ & $\mathrm{CH}_{2} \mathrm{OH}$ \\
\hline & \multirow[t]{2}{*}{$\mathrm{O} 2=0.416$} & & $\mathrm{C} 1-\mathrm{H}=1.091$ & $3.70 \mathrm{ppm}$ \\
\hline & & & $\mathrm{C} 2-\mathrm{H}=1.091$ & \\
\hline \multirow{8}{*}{$\begin{array}{l}\mathrm{HO}^{\prime} \\
\end{array}$} & $\mathrm{C} 1=0.022$ & \multirow[t]{4}{*}{$\mathrm{O} 1 \mathrm{C} 1 \mathrm{C} 2 \mathrm{O} 2=0.10$} & $\mathrm{C} 1-\mathrm{O} 1=1.420$ & $\mathrm{CH}_{2} \mathrm{OH}$ \\
\hline & $\mathrm{C} 2=0.022$ & & $\mathrm{C} 2-\mathrm{O} 2=1.420$ & $3.66 \mathrm{ppm}$ \\
\hline & $\mathrm{O} 1=0.414$ & & $\mathrm{C} 1-\mathrm{C} 2=1.542$ & $\mathrm{CH}_{2} \mathrm{O}$ \\
\hline & $\mathrm{O} 2=-0.414$ & & $\mathrm{C} 1,2-\mathrm{H}=1.090$ & $4.20 \mathrm{ppm}$ \\
\hline & $\mathrm{C} 1=0.022$ & $\mathrm{O} 1 \mathrm{C} 1 \mathrm{C} 2 \mathrm{O} 2=0.10$ & $\mathrm{C} 1-\mathrm{O} 1=1.420$ & $\mathrm{CH}_{2} \mathrm{O}$ \\
\hline & $\mathrm{C} 2=0.022$ & & $\mathrm{C} 2-\mathrm{O} 2=1.420$ & $3.67 \mathrm{ppm}$ \\
\hline & $\mathrm{O} 1=-0.414$ & & $\mathrm{C} 1-\mathrm{C} 2=1.542$ & \\
\hline & $\mathrm{O} 2=-0.414$ & & $\mathrm{C} 1-\mathrm{H}=1.090$ & \\
\hline & $C 1=-0.676$ & & $\mathrm{C} 1-\mathrm{O} 1=1.203$ & $\mathrm{CH}_{3}$ \\
\hline & $\mathrm{C} 2=0.452$ & & $\mathrm{C} 2-\mathrm{H}=1.107$ & $2.22 \mathrm{ppm}$ \\
\hline & $\mathrm{O} 1=-0.533$ & & & \\
\hline & $\mathrm{C} 1=0.023$ & $\mathrm{O} 1 \mathrm{C} 1 \mathrm{C} 2 \mathrm{O} 2=-17.95$ & $\mathrm{C} 1-\mathrm{O} 1=1.430$ & $\mathrm{CH}_{2} \mathrm{O}$ \\
\hline & $\mathrm{C} 2=0.024$ & $\mathrm{C} 3 \mathrm{O} 2 \mathrm{C} 2 \mathrm{C} 1=34.16$ & $\mathrm{C} 2-\mathrm{O} 2=1.422$ & $3.83-4.30 \mathrm{ppm}$ \\
\hline & $\mathrm{C} 3=0.450$ & $\mathrm{C} 3 \mathrm{O} 1 \mathrm{C} 1 \mathrm{C} 2=-4.91$ & $\mathrm{C} 1-\mathrm{C} 2=1.538$ & $\mathrm{CH}_{3}$ \\
\hline & $\mathrm{O} 1=-0.375$ & & $\mathrm{C} 3-\mathrm{O} 1=1.413$ & $1.40 \mathrm{ppm}$ \\
\hline & $\mathrm{O} 2=-0.425$ & & $\mathrm{C} 3-\mathrm{O} 2=1.423$ & \\
\hline 5 & & & $\mathrm{C} 1,2,3-\mathrm{H}=$ & \\
\hline$b$ & & & $1.090 ; 1.092 ; 1.101$ & \\
\hline
\end{tabular}




\section{3. Plausible Mechanism}

These interesting results then led us to propose an ionic mechanism to explain the formation of the mixture of three products 2, 3 and 5 from ethylene glycol (1) (Scheme 3). The first step in the conversion of ethylene glycol (1) to 2-methyl-1,3-dioxolane (5) is the reaction of 1,2-diol $\mathbf{1}$ with the Brønsted sites located on the active surface of the three catalysts $\mathrm{Al}$ com, $\mathrm{Si}$ com and Si syn to lead first, after the removal of water from the oxonium ion $\mathbf{A}$. In this case, there are three possibilities: the first one where this oxonium ion $\mathbf{A}$ undergoes directly the nucleophilic attack of ethylene glycol (1) in excess to lead to diethylene glycol (2) via oxonium ion $\mathbf{B}$. The dehydration of this dimer 2 initiated by heating in an acidic medium leads to oxonium ion $\mathbf{D}$. The intramolecular cyclisation of intermediate $\mathbf{D}$ gives 1,4-dioxane (3) (Scheme 3, route a). The second possibility is that oxonium ion A cyclises into protonated oxirane $\mathbf{C}$ which undergoes the nucleophilic addition of reagent $\mathbf{1}$ on methylenic carbon to lead to diethylene glycol (2) via oxonium ion B (Scheme 3, route b). Finally, the third way shows that this oxonium ion A undergoes a Wagner-Meerwein rearrangement, transforming it into a more stable secondary carbocation $\mathbf{E}$. The acetaldehyde (4) formed in situ will in turn be trapped by diol $\mathbf{1}$ to lead to the oxonium ion $\mathbf{F}$ which is converted into oxonium ions $\mathbf{G}$ and $\mathbf{I}$. Dehydration of the latter I leads to a tertiary carbocation which is cyclised by an intramolecular O-alkylation to 2-methyl-1,3-dioxolane (5) (Scheme 3, route $\mathrm{c}$ ).

We can then conclude that the spectral analysis confirms the experimental results well and that compound $\mathbf{5}$ is the main product of the conversion of ethylene glycol (1) and also the most thermodynamically stable product, which confirms its proportions in the obtained mixture. It should be noted that the other two products $\mathbf{2}$ and $\mathbf{3}$ are less stable and therefore have low proportions in the same mixture. In addition, we can note that in situ intermediates such as oxirane and acetaldehyde (4) are indeed the kinetic products in the conversion reaction of ethylene glycol (1) (Table 3).

\section{Conclusions}

In this work, we presented a new way of synthesising 2-methyl-1,3-dioxolane (5) using solid catalysts that meet the demands of environmental and green chemistry. From the obtained results, we have showed that the yields of diethylene glycol (2), 1,4-dioxane (3) and 2-methyl-1,3-di-

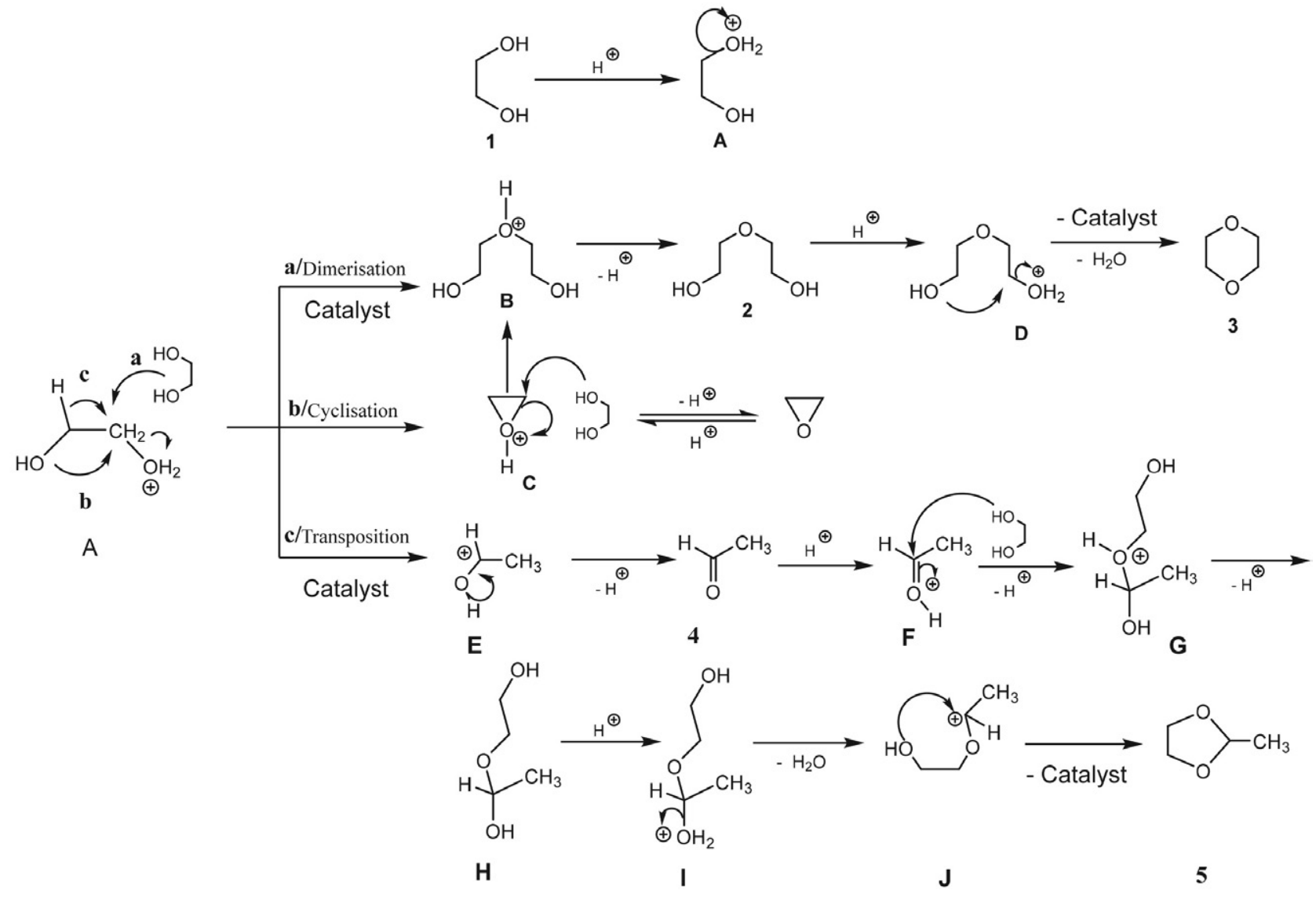

Scheme 3. 
oxolane (5) depends on the cation exchange capacity of alumina, silica gel and especially synthetic Moroccan silica. The rate of the acetalization reaction of acetaldehyde (4) formed in situ is more important than that of the dimerization reaction of ethylene glycol (1). In addition, synthetic silica is very effective in transforming ethylene glycol (1) to 2-methyl-1,3-dioxolane (5).

\section{Acknowledgments}

Prof. Dr. Taoufik Rohand thanks the University Cadi Ayyad and specially the Faculty Polydisciplinaire of Safi for the financial support to the LACM laboratory. Dr. Kiyoshi Tanemura thanks Nippon Dental University for the financial support to the Chemical Laboratory.

\section{Supporting Materials}

There is no supplementary information associated with this paper.

\section{References}

1. B. Hatano, S. Toyota, F. Toda, Green Chem., 2001, 3, 140-142. DOI: $10.1039 / \mathrm{b} 102447 \mathrm{~g}$

2. A. Sakakura, Y. Koshikari, K. Ishihara, Tetrahedron Lett., 2008, 49, 5017-5020. DOI:10.1016/j.tetlet.2008.06.058

3. F. Toda, T. Suzuki, S. Higa, J. Chem. Soc. - Perkin Trans. 1, 1998, 3521-3522. DOI:10.1039/a805884i

4. K. R. Prasad, P. Anbarasan, Tetrahedron Asymmetry, 2007, 18, 1419-1427. DOI:10.1016/j.tetasy.2007.05.014

5. H. K. Patney, Tetrahedron Lett., 1991, 32, 2259-2260.

DOI:10.1016/S0040-4039(00)79696-1

6. K. Wilson, J. H. Clark, Pure Appl. Chem., 2000, 72, 13131319. DOI:10.1351/pac200072071313

7. B. Pério, M. J. Dozias, P. Jacquault, J. Hamelin, Tetrahedron Lett., 1997, 38, 7867-7870.

DOI:10.1016/S0040-4039(97)10149-6
8. J. F. Knifton, Appl. Catal. A, Gen., 1995, 130, 79-88. DOI:10.1016/0926-860X(95)00090-9

9. M. Onaka, M. Kawai, Y. Izumi, Chem. Lett., 1985, 14, 779782. DOI: $10.1246 / \mathrm{cl} .1985 .779$

10. D. Schinzer, M. Kalesse, Synlett, 1989,1, 34-35. DOI:10.1055/s-1989-34704

11. S.Manfredini, D.Simoni, V.Zanirato, A.Casolari, Tetrahedron Lett., 1988, 29, 3997-4000. DOI:10.1016/S0040-4039(00)80403-7

12. T. Rohand, J. Savary, I. E. Markó, Monatsh. Chem., 2018, 149, 1429-1436. DOI:10.1007/s00706-018-2198-7

13. K. Tanemura, Tetrahedron Lett., 2018, 59, 4293-4298. DOI:10.1016/j.tetlet.2018.10.043

14. K. Tanemura, T. Rohand, Tetrahedron Lett., 2020, 61, 152142. DOI:10.1016/j.tetlet.2020.152142

15. A. Costa, J. Chem. Educ., 1982, 59, 1066. DOI:10.1021/ed059p1066

16. K. Bougrin, A. Loupy, M. Soufiaoui, Tetrahedron, 1998, 54, 8055-8064. DOI:10.1016/S0040-4020(98)00431-1

17. B. Syassi, K. Bougrin, M. Soufiaoui, Tetrahedron Lett., 1997, 38, 8855-8858. DOI:10.1016/S0040-4039(97)10392-6

18. K. P. C. Vollhardt, N. E. Schore: Traité de Chimie Organique, $4^{\text {ème }}$ Edit, De Boeck \& Larcier, Bruxelles, Bruxelles, 2004, p 760.

19. M. B. Smith: Organic Synthesis, McGraw-Hill, New York, 1994, p. 652.

20. T. W. Green, P. G. M. Wuts: Protective Groups in Organic Synthesis, Wiley Intersciences, New York, 1999, p. 308.

DOI:10.1002/0471220574

21. B. Joy, S. Ghosh, P. Padmaja, M. Lalithambika, Catal. Commun., 2005, 6, 573-577. DOI:10.1016/j.catcom.2005.04.021

22. N. A. Ghulam, M. N. Abbas, D. E. Sachit, Indian Chem. Eng., 2020, 62, 301-313. DOI:10.1080/00194506.2019.1677512

23. S. D. Barton, W. D. Ollis: Comprehensive Organic Chemistry, The Synthesis and Reactions of Organic Compounds, Pergamon Press, Paris, 1979, p. 881.

24. R. C. Elderfield: Heterocyclic Compounds, Six Membered Heterocycles Containing Two Heteroatoms and Their Benzo Derivatives, John Wiley \& Sons, New York, London, Chapman \& Hall, 1957, p. 3.

25. R. Grignard, J. Colonge: Précis de Chimie Organique, 4 ème Edit, Masson et Cie, 1958, p. 344.

\section{Povzetek}

Opisujemo kinetične in mehanistične študije nove poti kompetitivne pretvorbe etilen glikola ob prisotnosti alumijevega ali silicijevega oksida. Za pretvorbo etilen glikola v zmes dietilen glikola, 1,4-dioksana in 2-metil-1,3-dioksolana, $\mathrm{z}$ acetaldehidom kot vmesnim produktom, pri $150{ }^{\circ} \mathrm{C}$ in pod avtogenim tlakom brez prisotnega topila smo uporabili komercialno dostopnen aluminijev oksid ( $\mathrm{Al} \mathrm{com}$ ), sintetični aluminijev oksid ( $\mathrm{Al}$ syn), komercialno dostopni silikagel (Si com) in sintetični silikagel (Si syn). Rezultati kažejo, da so izkoristki vseh treh produktov močno odvisni od narave uporabljenega katalizatorja in reakcijskega časa.

Except when otherwise noted, articles in this journal are published under the terms and conditions of the Creative Commons Attribution 4.0 International License 